\title{
Correction to: Pluronic-Coated Biogenic Gold Nanoparticles for Colon Delivery of 5-Fluorouracil: In vitro and Ex vivo Studies
}

\author{
Wael A. Mahdi, ${ }^{1,6}$ Afzal Hussain, ${ }^{1,6}$ (i) Mohd Ramzan, ${ }^{2,3}$ Abdul Faruk, ${ }^{4}$ Sarah I. Bukhari, ${ }^{1}$ and Abhimanyu Dev ${ }^{5}$
}

Published online 22 February 2021

Correction to: AAPS PharmSciTech volume 22, Article number: 64 (2021) https://doi.org/10.1208/s12249-021-01922-1

During production, a type-setting error occurred in the acknowledgment section. The project number published was (IFKSURG-1442-443). The correct project number is (IFKSURG-1441-443).

The original article has been corrected.

Publisher's Note Springer Nature remains neutral with regard to jurisdictional claims in published maps and institutional affiliations.

The online version of the original article can be found at https:// doi.org/10.1208/s12249-021-01922-1

${ }^{1}$ Department of Pharmaceutics, College of Pharmacy, King Saud University, Riyadh, 11451, Saudi Arabia.

${ }^{2}$ Department of Pharmaceutics, PCTE Institute of Pharmacy, PTU, Ludhiana, Punjab, India.

${ }^{3}$ Department of Pharmaceutics, University Institute of Pharmaceutical Sciences, Panjab University, Chandigarh, Punjab, India.

${ }^{4}$ Department of Pharmaceutical Science, HNB Garhwal University (A Central University), Srinagar, Uttarakhand, India.

${ }^{5}$ Department of Pharmaceutical Sciences and Technology, Birla Institute of Technology, Mesra, Ranchi, Jharkhand 835215, India.

${ }^{6}$ To whom correspondence should be addressed. (e-mail: wmahdi@ksu.edu.saafzal.pharma@gmail.com) 